\title{
Unravelling the hydrocarbon charge history of a field using noble gases
}

\author{
J. A. SCOTT ${ }^{1 *}$, M. PUJOL ${ }^{1}$ \& S. M. V. GILFILLAN ${ }^{2}$ \\ ${ }^{1}$ Total E\&P, CSTFJ, Pau - 64000, France \\ (*james-alexander.scott@total.com) \\ 2 School of GeoSciences, University of Edinburgh, \\ Edinburgh, EH9 3FE, UK
}

Resolving the hydrocarbon charge history of a field is traditionally undertaken using organic geochemistry tools, e.g. vitrinite reflectance equivalence, biomarkers and stable isotopes. However, it is often difficult to quantify the order and the volume of fluid charges using such methods. We present a new approach for resolving the charge history and estimating the volumetric ratios of oil-water, gas-water and oil-gas using noble gases.

The noble gases ( $\mathrm{He}, \mathrm{Ne}, \mathrm{Ar}, \mathrm{Kr}$ and $\mathrm{Xe}$ ) are present in trace quantities in all crustal fluids. They do not react with or degrade within hydrocarbon reservoirs in the same manner as organic tracers. Their distribution in crustal fluids is the result of physical interactions between different fluid sources and phases [e.g. 1, 2].

The principle of using noble gases is relatively straightforward. When two fluids mix in the subsurface, the noble gases within the fluid will partition according to their relative solubility. The noble gases $\left({ }^{20} \mathrm{Ne},{ }^{36} \mathrm{Ar},{ }^{84} \mathrm{Kr}\right.$ and ${ }^{132} \mathrm{Xe}$ ) are practically absent in virgin hydrocarbon fluids. Therefore, any detection of these isotopes is indicative of interaction with water [3]. Noble gases have different solubilities in oil, water and gas, and therefore, partition differently depending on the fluid type. Using the model outlined by Bosch \& Mazor [4], it is possible to predict the partitioning patterns of noble gas in wateroil and water-gas systems.

Using noble gas data collected from a range of different fields, we present a new application of the Bosch \& Mazor method. Using this modified model, we demonstrate the utility of noble gases in resolving multiple charges of hydrocarbons, the charge history and the approximate volumetric ratios of the fluids.

[1] Pinti \& Marty (1995). GCA, 59(16), 3389-3404. [2] Kipfer, et al. (2002). Reviews in mineralogy and geochemistry, 47(1), 615-700. [3] Pujol, et al. (2018). Chem Geol., 480, 128-138. [4] Bosch \& Mazor (1988) EPSL, 87(3), 338-346. 